\title{
Causes and Consequences of Alternative SUCCESSIONAL TRAJECTORIES FOLLOWING THE 1988 YELLOWSTONE FIRES
}

\author{
MONICA G. TURNER $\uparrow$ UNIVERSITY OF WISCONSIN $\uparrow$ MADISON \\ William H. ROMME $\uparrow$ FORT LEWIS COLLEGE $\uparrow$ DURANGO $\uparrow \mathrm{CO}$ \\ DENNIS H. KNIGHT $\downarrow$ UNIVERSITY OF WYOMING $\downarrow$ LARAMIE \\ DANIEL B. TINKER $\uparrow$ WESTERN CAROLINA UNIVERSITY $\uparrow$ CULlOWHEE $\uparrow \mathrm{NC}$
}

\section{$\downarrow$ INTRODUCTION}

The 1988 Yellowstone fires created a strikingly heterogeneous pattern of severely burned, lightly burned, and unburned forests across a large portion of Yellowstone's subalpine Plateau (Turner et al. 1994). Equally striking has been the variation in post-fire tree seedling density throughout the burned forests. In 1999 we initiated a 3-year study of postfire succession, with three principal objectives:

(1) to document the variation in post-fire tree sapling density and to map the spatial patterns of sapling density to explain the causes of the variation in postfire sapling density to explore the consequences of variable post-fire sapling density for ecosystem processes, specifically aboveground net primary productivity (ANPP) and leaf area index (LAI).

We addressed the first objective by obtaining new, high-resolution aerial photographs of the entire park, sampling a number ground-truth points, and generating a map of sapling density within all of the areas that burned in 1988. For the second objective, we will test three hypotheses about causes of pattern by generating a predicted map of sapling density in a GIS environment (based on the hypotheses) and comparing the patterns generated by the predicted map with actual patterns documented in our empirical map produced from the aerial photos. The three hypotheses about causes of pattern were derived from our previous work (Turner et al. 1997) which showed that residual vegetation that survived the fire was the principal source of biotic cover in the first decade after fire. The most important biotic residual for tree establishment was lodgepole pine seeds that survived in the burned canopy, especially within serotinous cones (Tinker et al. 1994). The three hypotheses that we will test in this second objective are:

(a) Where pre-fire serotiny was high, highdensity stands have developed after the fires. Fire size and severity make little difference in this situation.

(b) Where pre-fire serotiny was low, fire severity largely determines post-fire sapling density. Moderate-density stands have developed in areas of severe surface fire, 
while low-density stands have developed in areas of crown fire (because of greater seed mortality in crown fires).

(c) Where pre-fire serotiny was zero, patch size largely determines post-fire sapling density. Low-density stands have developed in small burn patches (because of seed dispersal from adjacent unburned areas), while "non-forest" stands have developed in large burn patches. By "non-forest," we mean stands that were forested before the fire but that now have < 100 saplings / ha.

For the third objective, we focused on ANPP and LAI, because these are indicators of overall ecosystem function. ANPP is highly correlated with total energy flow in the system, and provides the base of the food web. LAI is strongly correlated with primary productivity and transpiration rate.

\section{$\uparrow \quad$ MethODS}

For the first objective, we obtained new GPS-controlled aerial photos (1:30,000 color infrared) of the entire Park in August, 1998. During the winter, we processed the photos to create a preliminary map of sapling density. During the 1999 field season we tested the predictions of the preliminary map in 88 stands distributed throughout the areas burned in 1988. In each of the 88 stands (each ca. 1 ha in extent), we measured sapling density in a belt transect, and also collected data for the third objective (below). Our findings led us to develop a new map of sapling density using objective classification methods (described in Results below).

For the second objective, we plan to predict sapling density in a large number of locations, based on our GIS coverages of \% serotiny, elevation, and 1988 burn patterns. We will then compare these predictions with actual sapling density as revealed by our final map derived from the aerial photos.

For the third objective, we harvested lodgepole pine saplings in five stands and determined ANPP and LAI using techniques of dimension analysis (Reed et al. 1999). From these samples we developed regression equations to predict ANPP and LAI from sapling basal diameter and height. We also developed regressions between \% cover (based on visual estimates) and ANPP and LAI for herbaceous species. Using these regressions we estimated total ANPP and LAI in all 88 stands sampled for testing the aerial photo interpretation (described above). Finally, we scaled up to the entire landscape by predicting ANPP and LAI in all burned patches on the basis of our measured relationship between sapling density and total stand ANPP and LAI.

\section{RESULTS}

.The preliminary map, based on visual interpretation of the aerial photos, was useful in identifying areas for field sampling. However, it failed to capture the degree of complexity that actually existed on the ground. Our field measurements revealed that post-fire sapling density ranged from $<10$ to $>500,000$ stems $/$ ha - some six orders of magnitude! Sapling density may vary 10 to 100 -fold over distances of only hundreds of meters. Because the preliminary map was judged inadequate to characterize the fine-scale heterogeneity that exists on the ground, we are in the process of developing a new map by means of supervised classification, using the 88 sampled stands as a training set. This new classification is still in progress.

The testing of hypothesized causes of the observed variation in sapling density (objective \#2) has not yet been completed, but will be pending completion of the final density map based on the aerial photos (objective \#1).

For the third objective, we found that ANPP was closely related to sapling density (positive correlation), but the herbaceous productivity declined with sapling density ( $78 \%$ of the total ANPP in the stands with 1000 stems/ha or less and $5-16 \%$ in stands with $>25,000$ stems $/$ ha). The ratio of herbaceous to tree ANPP varied over four orders of magnitude. Additional analyses are in progress.

\section{DISCUSSION}

The 1988 Yellowstone fires created a remarkably heterogeneous landscape. Post-fire sapling density varies over six orders of magnitude, within a very fine-grained pattern. Highest density is found in areas where pre-fire serotiny was high, and lowest density is found in large burned patches where none of the trees that burned had serotinous cones. To date, little thinning of the pine saplings that germinated after 1988 has taken place, even in very dense stands. 
Parameters of ecosystem function, viz. ANPP and LAI, are strongly correlated with post-fire sapling density. Overall, recovery of ecosystem function (as measured by ANPP and LAI) has been very rapid. Indeed, ANPP and LAI in high-density stands are within or nearly within the range reported for mature pine forests Reed et al. (1999).

\section{$\downarrow$ ACKNOWLEDGMENTS}

We thank our 1999 summer field crew for their hard work and diligence. We also thank Dr. Frank Scarpace, University of Wisconsin, for assistance in obtaining and interpreting the aerial photos. This research was funded by the National Science Foundation. Housing and logistical support were provided by the University of Wyoming National Park Service Research Center. The Yellowstone Center for Resources and the Yellowstone Ranger Division furnished assistance throughout the field season.

\section{LITERATURE CITED}

Reed, R. A., M. E. Finley, W. H. Romme, and M. G. Turner. 1999. Aboveground net primary production and leaf-area index in early postfire vegetation in Yellowstone National Park. Ecosystems 2:88-94.

Tinker, D.B., W.H. Romme, W.W. Hargrove, R.H. Gardner, and M.G. Turner. 1994. Landscape-scale heterogeneity in lodgepole pine serotiny. Canadian Journal of Forest Research 24:897-903.

Turner, M. G., W. W. Hargrove, R. H. Gardner, and W. H. Romme. 1994. Effects of fire on landscape heterogreneity in Yellowstone National Park, Wyoming. Journal of Vegetation Science 5:731-742.

Turner, M. G., W. H. Romme, R. H. Gardner, and W. W. Hargrove. 1997. Effects of fire size and pattern on early succession in Yellowstone National Park. Ecological Monographs 67:411-433. 